\title{
PENDARAHAN BERULANG SETELAH 14 TAHUN PADA MALFORMASI ARTERIOVENA DI SEREBELARIS
}

\author{
THE LATE ONSET RE-BLEEDING AFTER 14 YEARS OF RUPTURE CEREBELLAR AVM
}

Ni Nyoman Ayu Trisnadewi, * Kumara Tini*

\begin{abstract}
The arteriovenous malformation (AVM), a form of abnormality in brain vascularization, in the cerebellum is a rare disorder. The risk of recurrent bleeding after initial episode at five years is very low about 3,67\%. We reported a case of 25 years-old man with history of recurrent bleeding after 14 years with hydrocephalus as complication. The brain CT scan showed a bleeding in the cerebellar vermis with non-communicant hydrocephalus. The Digital Subtraction Angiography (DSA) showed a moderate left cerebellar AVM with high-flow plexiform nidus, left superior cerebellar artery as primary feeding artery with supplementary supply of the vein draining from the superior cerebellar artery to superior petrosal vein leading to the superior petrosal vein toward the contralateral transverse sinus and left sigmoid sinus. Embolization for infratentorial posterior fossa AVM bleeding needs to be considered even though previous bleeding occurs over 5 years to prevent re-bleeding.
\end{abstract}

Keywords: Arteriovenous malformation, embolization, feeding artery, nidus

\section{ABSTRAK}

Kelainan pembuluh darah malformasi arteriovena (MAV) pada serebelum merupakan kelainan vaskular yang jarang terjadi. Risiko pendarahan berulang setelah tahun kelima adalah rendah sekitar 3,67\%. Dilaporkan suatu kasus laki-laki, 25 tahun, dengan riwayat pendarahan serebri berulang setelah 14 tahun dengan komplikasi hidrosefalus. CT scan kepala menunjukkan adanya pendarahan pada bagian vermis dengan hidrosefalus non-komunikan. Pemeriksaan DSA (digital subtraction angiography) menunjukkan adanya MAV fosa posterior di serebelum kiri ukuran sedang dengan nidus pleksiformis high flow dan feeder utama arteri serebelaris superior kiri ke vena petrosal superior menuju ke sinus transversus kontralateral dan sinus sigmoid kiri. Tata laksana embolisasi pada MAV infratentorial fosa posterior yang mengalami pendarahan perlu dipertimbangkan walaupun pendarahan sebelumnya terjadi lebih dari 5 tahun untuk mencegah pendarahan kembali.

Kata kunci: Embolisasi, feeding arteri, malformasi arteriovena, nidus

*Departemen Neurologi FK Universitas Udayana/RSUP Sanglah, Denpasar. Korespondensi: ayutrisna0608@gmail.com.

\section{PENDAHULUAN}

Malformasi arteriovena (MAV) merupakan anomali kongenital pembuluh darah dari perkembangan kapiler yang abnormal, yang menyebabkan adanya hubungan langsung antara arteri serebral dan vena. Hal ini menimbulkan gejala pendarahan akibat rupturnya hubungan tersebut, ${ }^{1-2}$ membuat MAV sebagai penyebab pendarahan intraserebral nontraumatik terbanyak pada usia $<35$ tahun dengan insiden sekitar 1:200.000 orang setiap tahunnya. ${ }^{3}$ Pendarahan pada MAV dihubungkan dengan mortalitas dan morbiditas yang signifikan, serta beban biaya kesehatan selama terapi. ${ }^{4}$

Masalah pada MAV adalah risiko untuk pendarahan berulang, antara lain pada lokasi di batang otak atau infratentorial..$^{2-3}$ Risiko ruptur berulang lebih tinggi pada tahun pertama (6-15\%) dan menurun terutama setelah tahun kelima dengan mortalitas dan morbiditas $54 \%$ lebih besar dibandingkan ruptur sebelumnya. ${ }^{4}$ Berikut ini akan dipaparkan kasus MAV infratentorial dengan pendarahan berulang setelah 14 tahun yang merupakan kasus yang sangat jarang terjadi.

\section{KASUS}

Pasien laki-laki, 25 tahun, dibawa oleh keluarga ke IGD RSUP Sanglah karena ditemukan tidak sadar di dalam kamar sekitar dua jam sebelum masuk RS. Pasien mengeluhkan nyeri kepala berdenyut sejak 3 hari sebelumnya. Pasien memiliki riwayat pendarahan serebri kurang lebih 14 tahun yang lalu saat pasien duduk di bangku SMP tanpa riwayat trauma, terkonfirmasi dengan data rekam medis pasien sebelumnya dengan kecurigaan suatu anomali vaskular sebagai penyebab pendarahan yang 


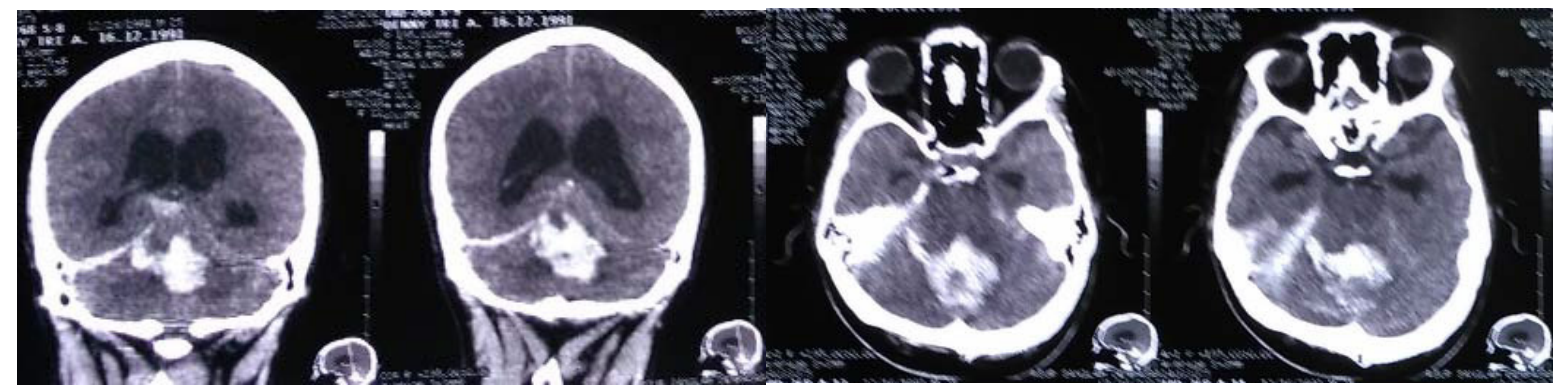

(a)

(b)

Gambar 1. Gambaran CT Scan Kepala

(a) potongan koronal dan aksial (b) tampak lesi hiperdense di area vermis serebelum, meluas dengan mengisi ventrikel ketiga, sulkus, serta kesan hidrosefalus nonkomunikan.

terjadi. Tidak ada riwayat penyakit atau keluhan lain, tidak ada anggota keluarga dengan sakit yang sama.

Pemeriksaan fisik di IGD didapatkan tekanan darah 150/90mmHg, Skala Koma Glasgow (SKG) E3V4M5=12, terdapat kaku kuduk, lain-lain dalam batas normal. Hasil pemeriksaan CT scan kepala didapatkan adanya lesi hiperdense di area vermis serebelum, meluas mengisi ventrikel ketiga, sulkus, dan hidrosefalus non-komunikan. Pasien di diagnosis dengan stroke hemoragik dengan hidrosefalus nonkomunikan dan dilakukan tindakan pemasangan pirau ventrikuloperitoneal (VP shunt) cito untuk mengatasi kegawatdaruratannya. Pasien dirawat selama 3 minggu dengan kondisi pulang kesadaran kompos mentis, disartria serebelar, dan penurunan tonus (hipotoni) tubuh sebelah kiri (Gambar 1). Selama perawatan pasien mendapatkan terapi cairan Nacl 0,9\%, paracetamol 1000mg tiap 8 jam oral, dan nimodipin 2,1 cc/jam intravena.

Pemeriksaan DSA dilakukan empat bulan kemudian, didapatkan gambaran MAV pada serebelum kiri ukuran sedang dengan nidus pleksiformis dan high flow, feeder utama arteri serebelaris superior kiri dengan suplai suplementar dari single draining vein menuju ke vena-vena hemisfer serebelum selanjutnya ke vena petrosal superior menuju ke sinus transversus kontralateral dan sinus sigmoid kiri. Tindakan embolisasi kuratif dilakukan dua bulan setelah pemeriksaan DSA atas pertimbangan risiko pendarahan berulang kembali, lokasi, dan karakteristik MAV untuk mengeliminasi MAV dari sirkulasi posterior. Embolisasi dilakukan dengan glue pada nidus MAV yang mendapat suplai dari arteri serebelaris superior kiri. Selanjutnya pasien rutin kontrol ke poli saraf RSUP Sanglah dengan kondisi disartria serebelar yang membaik (Gambar 2).

\section{PEMBAHASAN}

Pendarahan serebral dan kejang merupakan gejala yang paling sering terjadi pada MAV. ${ }^{2,5}$ Arteriol yang patologis pada MAV tidak memiliki otot polos seperti normalnya pembuluh darah, berhubungan langsung dengan vena melalui saluran yang melebar (nidus). ${ }^{6}$ Darah dari arteri dengan tekanan lebih tinggi menuju vena menyebabkan penebalan dinding vena yang berisiko pecah dan terjadi pendarahan. Angiografi merupakan pemeriksaan baku emas untuk mengetahui karakteristik nidus, pembuluh darah feeding, drainase, serta risiko pendarahan pada $\mathrm{MAV}^{2,6,8}$

Insiden MAV pertahun sekitar 1:100.000 dengan prevalensi 18 per 100.000 penduduk..$^{1,3}$ Berdasarkan lokasinya, MAV infratentorial (fosa posterior) sangat jarang terjadi dibandingkan MAV supratentorial dengan rata-rata kejadian $<15 \%$ dari seluruh MAV. ${ }^{5}$ Malformasi arteriovena yang belum ruptur memiliki tingkat pendarahan sekitar 1-3\% per tahun, dan sekitar $4,5 \%$ untuk MAV yang ruptur dari suatu meta-analisis. ${ }^{9}$ Studi dari Toronto mendapatkan bahwa risiko pendarahan sekitar $9,65 \%$ pada tahun pertama dan sekitar 3,67\% setelah lima tahun dari gejala pendarahan awal. ${ }^{1}$

Risiko pendarahan serebral meningkat jika pasien memiliki episode pendarahan sebelumnya atau jika malformasi terletak lebih dalam terutama fosa posterior baik serebelum atau batang otak..$^{7-9}$ Angio-arsitektur MAV dengan ukuran kecil $(<3 \mathrm{~cm})$, drainase vena yang lebih sedikit dan dalam, jumlah 


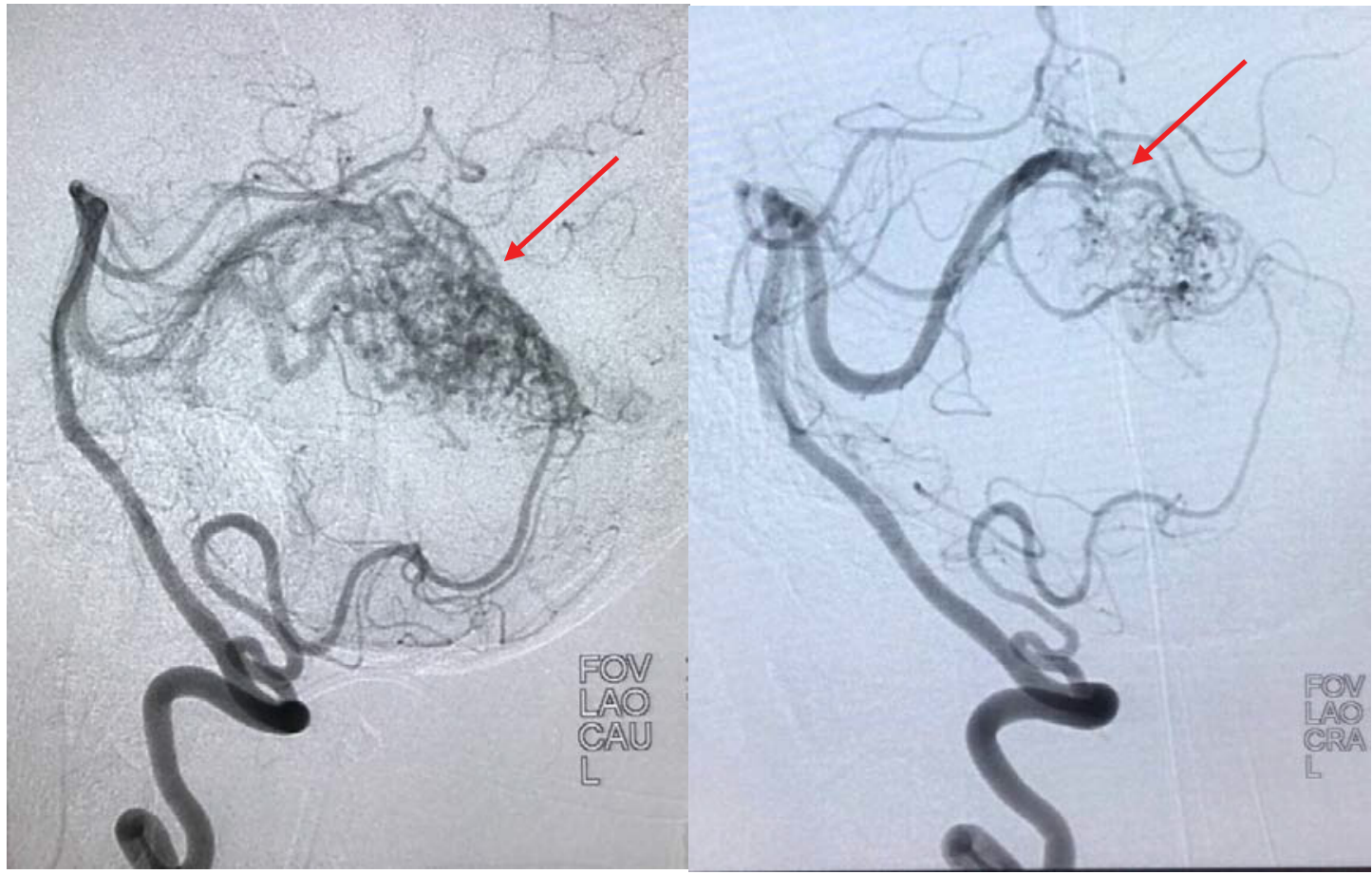

(a)

Gambar 2. Hasil Pemeriksaan DSA

(b)

(a) sebelum tindakan embolisasi, tampak adanya MAV pada serebelum kiri ukuran sedang; (b) pasca-embolisasi, tampak MAV menghilang dengan gambaran angiogenesis di sekitarnya.

feeding arteri yang banyak pada MAV, serta adanya aneurisma yang bersamaan dengan MAV menjadi faktor risiko terjadinya pendarahan dan pendarahan berulang. ${ }^{7-8}$ Faktor demografi menunjukkan perempuan memiliki risiko pendarahan lebih tinggi dibandingkan laki-laki, begitu juga dengan usia muda dan usia tua dihubungkan dengan risiko pendarahan lebih tinggi. Namun peningkatan usia menjadi faktor independen untuk pendarahan berulang. ${ }^{8-9}$

Pasien pada laporan kasus ini laki-laki, memiliki riwayat stroke pendarahan pada usia muda dicurigai suatu kelainan anomali vaskular, dan menderita stroke pendarahan berulang dalam waktu 14 tahun dengan hasil DSA terdapat MAV serebelar. Angioarsitektur MAV serebelar pada pasien berukuran sedang dan feeder arteri yang tunggal memiliki risiko pendarahan berulang lebih kecil dibandingkan MAV yang berukuran kecil $(<3 \mathrm{~cm})$ dan banyak feeding arteri. MAV dengan high flow dan single draining vein yang dalam berisiko tinggi untuk terjadi pendarahan berulang. ${ }^{7-8,10}$

Terapi dipilih tergantung dari kondisi klinis, ukuran, lokasi, angio-arsitektur dari MAV, umur pasien, dan komorbiditas riwayat pendarahan. ${ }^{11-12}$
Terapi definitif harus dapat menghilangkan nidus dan shunt arteriovenous komplit sehingga mencegah pendarahan berulang. ${ }^{6}$ Sampai saat ini untuk MAV pada fosa posterior lebih menguntungkan dengan tindakan endovaskular. ${ }^{11,13}$ Tindakan endovaskular secara permanen dapat mengurangi ukuran MAV dan aliran darah yang abnormal sehingga menurunkan insiden pendarahan sekunder dengan resiko yang minimal untuk pasien. ${ }^{13}$

Pasien dilakukan tindakan VP shunt cito untuk mengatasi komplikasi sekunder, yaitu hidrosefalus. MAV pada pasien ini berukuran sedang, satu feeding arteri dan drainase vena dalam, sehingga dilakukan tindakan embolisasi sebagai terapi definitif walaupun tanpa ada stenosis vena. Embolisasi dipilih menimbang dari lokasi MAV yang dalam serta ukuran MAV yang sedang bisa dikerjakan dengan tindakan endovaskular. ${ }^{13}$

Risiko munculnya defisit neurologis pascatindakan operatif lebih besar sekitar 21,5\% ditambahkan angka $20 \%$ pada drainase venanya yang dalam, sehingga lebih dipilih untuk tindakan embolisasi. ${ }^{1}$ Terapi embolisasi endovaskular pada MAV yang berukuran sedang $(>3 \mathrm{~cm})$ memiliki 
prognosis yang lebih baik dibandingkan diameter kecil $(<3 \mathrm{~cm})$ dengan tingkat mortalitas $1,3 \%$ dan komplikasi sedang dan berat berturut-turut sekitar $15,3 \%$ dan $6,7 \%{ }^{14}$ Terapi endovaskular embolisasi pernah dilaporkan sebagai terapi utama pada kasus anak 11 tahun dengan MAV serebelar dan didapatkan hasil DSA enam bulan pascatindakan oklusi MAV total dengan gejala asimptomatik pada pasien. ${ }^{15}$

Hasil DSA pascatindakan embolisasi pada pasien ini tidak didapatkan lagi malformasi dengan klinis disatria yang membaik.

\section{KESIMPULAN}

Arteriovenous malformasi terutama pada fosa posterior sangat jarang terjadi. Manifestasi utama adanya pendarahan yang mendadak apabila terjadi ruptur dan kondisi sekunder seperti hidrosefalus yang memerlukan tindakan operatif awal untuk mengatasi komplikasi yang terjadi. Tingkat pendarahan kembali dikatakan berkurang setelah tahun pertama namun tetap menjadi ancaman bagi pasien terutama MAV fosa posterior. Tindakan endovaskular embolisasi tetap menjadi pilihan utama kasus MAV fosa posterior dengan luaran yang baik, walaupun risiko pendarahan berulang setelah lima tahun menurun. Tindakan endovaskular perlu dipertimbangkan untuk mencegah pendarahan kembali.

\section{DAFTAR PUSTAKA}

1. Ajiboye N, Chalouhi N, Starke R, Zanaty M, Bell R. Cerebral arteriovenous malformation: evaluation and management. Scientific World Journal. 2014;16:1-6.

2. Solomon R, Connolly S. Arteriovenous malformation of the brain. N Engl J Med. 2017;376(19):1859-66.

3. Shotar E, Pistocchi S, Haffar I, Bartolini B, Jacquens, Nouet A, dkk. Early rebleeding after brain arteriovenous malformation rupture, clinical impact and predictive factors: a monocentric retrospective cohort study. Cerebrovasc Dis. 2017;44(4-6):304-12.

4. Bradley A, Du R. Rate of re-bleeding of arteriovenous in the first year after rupture. J Neurol Sci. 2012;19(8):1087-88.
5. Neacsu A, Mircea R, Gorgan, Bucur N, Sandu A, Viori M. Posterior fossa malformation-case report. RSN. 2015;16(1):1-4.

6. Derdeyn CP, Zipfel GJ, Albuquerque FC, Cooke DL, Feldmann E, Sheehan JP, dkk. Management of brain arteriovenous malformation. Stroke. 2017;48(8):13460.

7. Xiaolong D, Wang S, Shenjun L, Wang Z, Xing H, Wei G, dkk. Risk factors for hemorrhage in patient with cerebral arteriovenous malformations. Int J Cllin Exp Med. 2016;9(3):6649-55.

8. Robert T, Blanc R, Cicio G, Redjem H, Fahed R, Smajda S, dkk. Anatomic and angiographic findings of cerebellar arteriovenous malformation: report of a single center experience. J Neurol Sci. 2015;358(12):357-61.

9. Xianli Lv, Xiulan Hu, Youxiang L. The Influence of age and the initial clinical presentation of patient with an arteriovenous malformation on the risk of hemorrhage. Neurol India. 2016;64(1):87-94.

10. Rutledge WC, Ko NU, Lawton MT, Kim H. Hemorrhage rates and risk factors in the natural history course of brain arteriovenous malformation. Transl Stroke Res. 2014;5(5):538-42.

11. Magro E, Chainey J, Chalala C, AL Jehani H, Fournier J, Bojanowski MW. Management of ruptured posterior fossa arteriovenous malformation. Clin Neurol Neurosurg. 2015;128:78-83.

12. Danaila L. The cerebellar arteriovenous malformation. Proc Rom Acad. 2015;17(2):95-110.

13. Ellis JA, Lavine SD. Role of embolization for cerebral arteriovenous malformation. MDCVJ. 2014;X(4):234-9.

14. Guobin L, Kun H, Haiying Y, Hui H, Hong Y, Dezhang Z. Risk factors of intracranial hemorrhage after brain AVM interventional therapy and its effect on prognosis. Int J Clin Exp Med. 2015;8(7):11014-9.

15. Renier L, Nicola L, Arturo C, Andrea R, Sergo N, Flavio G, dkk. Transvenous embolization: a report of 4 pediatric cases. J Neurosurg pediatr. 2015;15(10):445-50. 